\title{
HETEROTÔNICOS ENTRE A LÍNGUA PORTUGUESA E A ESPANHOLA NO ÂMBITO DAS CIÊNCIAS DA SAÚDE
}

\author{
FALSOS AMIGOS PROSÓDICOS ENTRE LA LENGUA PORTUGUESA Y LA \\ ESPAÑOLA EN EL ÁMBITO DE LAS CIENCIAS DE LA SALUD
}

SPANISH AND PORTUGUESE 'HETEROTÔNICOS' IN THE FIELD OF MEDICINE

\author{
Ana María DÍAZ FERRERO ${ }^{1}$
}

RESUMO: Este trabalho está integrado num projeto de pesquisa cujo objetivo é realizar um estudo tipológico de falsos amigos em português e espanhol e elaborar material didático específico destinado a facilitar a aquisição destas unidades, assim como evitar as interferências que podem provocar num processo de aprendizagem do português como língua estrangeira. Neste artigo propomos uma classificação de heterotônicos, isto é, palavras iguais ou semelhantes em português e espanhol tanto na forma quanto no significado que apresentam a sílaba tônica numa posição diferente em cada língua. Nas últimas décadas os estudos sobre ensino e aprendizagem do vocabulário mostram as vantagens de realizar redes associativas como estratégia didática para desenvolver a competência lexical. Neste sentido, empregando critérios semânticos e morfológicos de associação léxica, elaboramos um repertório lexicográfico de heterotônicos relativos à área das ciências da saúde.

PALAVRAS-CHAVE: Heterotônicos. Espanhol. Português para fins específicos. Linguagem médica.

RESUMEN: Este trabajo se integra en un proyecto cuyo objetivo es realizar un estudio tipológico de falsos amigos en portugués y español, y elaborar material didáctico específico destinado a facilitar su adquisición y evitar las interferencias que pueden provocar en el proceso de aprendizaje del portugués como lengua extranjera. En este artículo proponemos una clasificación de heterotónicos, es decir, vocablos iguales o semejantes en portugués y español tanto en la forma como en el significado que presentan la sílaba tónica en una posición distinta en cada lengua. En las últimas décadas los estudios realizados sobre enseñanza y aprendizaje del léxico ponen de manifiesto las ventajas de realizar redes asociativas como estrategia didáctica para desarrollar la competencia léxica. En este sentido, siguiendo criterios semánticos y morfológicos de asociación léxica elaboramos un repertorio lexicográfico de términos heterotónicos pertenecientes al área de las ciencias de la salud.

PALABRAS CLAVE: Falsos amigos. Prosodia. Español. Portugués para fines específicos. Lenguaje médico.

1 Universidad de Granada (UGR) - Granada - España. Doctora en Filología Románica. Profesora del Departamento de Traducción e Interpretación. ORCID: <http://orcid.org/0000-0002-0916-5552>. E-mail: anadiaz@ugr.es 
ABSTRACT: This work is integrated into a project whose objective is to carry out a typological study of false friends in Portuguese and Spanish, and to create specific educational material intended to make their acquisition easier and avoid the interference which the process of learning Portuguese as a foreign language can cause. In this article we propose a classification of 'heterotônicos', that is to say, words which are the same, in both form and meaning, in Portuguese and Spanish, with the stressed syllable in a different position in each language. In the last few decades, the studies which have been carried out on the teaching and learning of vocabulary highlight the advantages of making associative networks as an educational strategy for developing lexical competence. Following semantic and morphological criteria of association, we have created a lexical repertoire of 'heterotônicos' terms belonging to the area of health sciences.

KEYWORDS: False friends. Spanish. Portuguese for specific purposes. Medical language.

\section{Introducción}

En la Universidad de Granada estamos trabajando en un proyecto de investigación cuyo objetivo es analizar las aparentes simetrías léxicas entre el español y el portugués, y elaborar un corpus global de falsos amigos entre ambas lenguas. Para ello, partimos de un concepto integral de falso amigo que definimos como unidad léxica de la lengua extranjera con forma idéntica o parecida a la lengua materna que oculta alguna divergencia susceptible de pasar inadvertida y provocar un error o inadecuación de comprensión o expresión escrita u oral. Distinguimos cinco grupos de falsos amigos clasificados según el tipo de error o inadecuación que pueden originar: falsos amigos prosódicos; falsos amigos morfológicos y sintácticos; falsos amigos ortográficos y ortotipográficos; falsos amigos semánticos y falsos amigos pragmáticos. Los falsos amigos prosódicos son los que pueden ocasionar errores de pronunciación, concretamente de alteración de la sílaba tónica; falsos amigos morfológicos y sintácticos son los que pueden provocar alteraciones de género, número o de sintaxis, entre otros; falsos amigos ortográficos y ortotipográficos son susceptibles de originar fallos de ortografía o de signos tipográficos; falsos amigos semánticos pueden inducir a erróneas interpretaciones respecto al sentido de una palabra o unidad fraseológica; y, finalmente, falsos amigos pragmáticos son los que pueden dar lugar a que un vocablo o unidad léxica se utilice en el contexto o en la situación comunicativa inadecuada por tener diferencias de uso en cada lengua.

El objetivo central de este proyecto es analizar los falsos amigos en portugués y español y elaborar material didáctico específico destinado a facilitar su adquisición y evitar las interferencias que pueden provocar en el proceso de aprendizaje del portugués como lengua extranjera. Parte de los resultados de este proyecto ya han sido publicados en un 
manual de falsos amigos semánticos (DÍAZ FERRERO, 2013). En el presente artículo nos centraremos en los falsos amigos prosódicos. La prosodia es la parte de la gramática que estudia la correcta pronunciación y acentuación de las palabras, y comprende diversos aspectos como la entonación, el ritmo, la duración y la tonicidad de la sílaba. En concreto ofrecemos una clasificación de heterotónicos siguiendo diferentes estrategias de asociación léxica para que sea útil como fuente lexicográfica para la didáctica del portugués para fines específicos. Son vocablos pertenecientes al área de la salud iguales o semejantes en español y en portugués tanto en la forma como en el significado, que se diferencian por presentar la sílaba tónica en una posición distinta en cada una de las lenguas. Por ejemplo, las palabras españolas terapia, linfocito, síntoma, albúmina, naturópata o dislexia respecto a las portuguesas terapia, linfócito, sintoma, albumina, naturapata o dislexia.

\section{Marco teórico. Estudios sobre heterotónicos en español y portugués}

No existe una terminología unificada para designar los falsos amigos con asimetrías de sílaba tónica. Los investigadores emplean distintos términos para designar estos vocablos: 'heterotônicos' (BECKER, 1967; MILANI, 1999; ALVES, 2003; SILVEIRA, 2008), 'heterotónicos' (ANDRADE NETA, 2000; SERRA; BERTELEGNI; ABREU, 2007; MASIP, 2013), 'heteroprosódicos' (MARRONE, 1990) o 'falsos amigos prosódicos' (CARLUCCI; DÍAZ, 2007). En este trabajo utilizaremos indistintamente las denominaciones heterotónico y falso amigo prosódico: el primero porque tiene un amplio uso en portugués, principalmente en Brasil como veremos a continuación, y el segundo porque el término 'falso amigo' es el que se emplea en España habitualmente para designar vocablos engañosos de dos lenguas, y 'prosódico' hace referencia al tipo de error que puede originar.

Entre los investigadores brasileños este asunto suscita desde hace décadas un considerable interés. Según nuestras pesquisas, el primero de ellos fue Antenor Nascentes que en su "Esbozo de Comparación del español con el portugués" publicado en 1936 ya señalaba discrepancias en la acentuación entre estas lenguas. Una década después, en esta línea de análisis contrastivo del español y el portugués, el profesor Idel Becker publicó en 1945 su "Manual de Español", donde incluía una clasificación de vocablos divergentes entre los que se encontraban los heteroprosódicos que a su vez los subdividía en heterofónicos y heterotónicos. La metodología tradicional y el enfoque establecido por Nascentes y Becker ha sido una referencia constante en la enseñanza del español en Brasil, de ahí que los términos 
heteroprosódico y heterotônico se sigan utilizando ampliamente en este país en los trabajos dedicados al estudio y al análisis de estos falsos amigos. Con todo, las investigaciones en los últimos años se realizan desde perspectivas mucho más profundas y enriquecedoras como son: explicar el proceso de cambio lingüístico que ha dado origen a las divergencias prosódicas entre estas dos lenguas analizando el origen etimológico de algunas palabras heterotónicas (MARRONE, 1990; BRAGA; DURÃO, 2000); comprender los factores fonéticos y fonológicos que han contribuido a que se produzca una divergencia en el sistema acentual en estos vocablos desde una perspectiva evolutiva (GARCÍA YEBRA, 1999a; 1999b; 2003; MASIP, 2013) o analizar aspectos didácticos relacionados con estos términos (BENEDETTI, 2002; SILVEIRA, 2008).

Dada la similitud de estas dos lenguas se puede transferir con éxito en muchos casos la tonicidad de una lengua a la otra. No obstante, cuando aparecen términos heterotónicos en el discurso, si el nivel de competencia linguiística no es elevado, existe riesgo de interferencia o transferencia errónea de la sílaba tónica de la lengua materna sobre la lengua extranjera. Estos vocablos pueden provocar errores de pronunciación cuando no van acentuados gráficamente, o en situaciones en las que el hablante no tiene acceso directo al texto escrito y por desconocimiento, mimetismo o simplemente incompetencia lingüística reproduce la tonicidad de una lengua en la otra. Estos errores no suelen interferir en la comprensión del mensaje y quizás por ello a este aspecto contrastivo de la lengua se le presta poca atención, a pesar de ser un rasgo distintivo de alta competencia lingüística. Como señalan Serra, Bertelegni, y Abreu en su manual "Fonética aplicada a la enseñanza del español como lengua extranjera. Un curso para lusófonos" estos vocablos "no suelen provocar interferencias significativas en la comunicación. Sin embargo, si lo que se busca es el perfeccionamiento de la lengua en estudio, este será un problema fonético que deberá ser superado" (SERRA; BERTELEGNI; ABREU, 2007, p. 59). En este mismo sentido el profesor Enrique Santamaría, en un artículo sobre la enseñanza de la prosodia en el español como lengua extranjera, considera que este es un aspecto frecuentemente desatendido en el aula y todavía existe la idea "de que la prosodia es un fenómeno de adquisición automática y que, por lo tanto, a la manera de los nativos, se aprende de oído" (SANTAMARÍA, 2007, p. 1238). Estamos de acuerdo con esta afirmación y consideramos que en el caso del portugués como lengua extranjera también la tonicidad es un aspecto poco tratado en los manuales y ello puede ser la causa de que estos vocablos provoquen desvíos de la norma o interferencias prosódicas entre el portugués y el español. 
Algunos diccionarios bilingües de estas lenguas (MINIDICIONÁRIO Saraiva, 2011; DÍAZ; GARCÍA TALAVERA, 2008; VOLPI, 2005; MASIP, 2013), así como gramáticas y manuales de español para extranjeros dirigidos a lusohablantes o de portugués para hablantes de español (DUARTE, 1999; MORENO; FERNÁNDEZ, 2007; SERRA; BERTELEGNI; ABREU, 2007) llaman la atención del lector sobre las diferencias respecto a la posición acentual entre estas lenguas, pero se hace necesario un análisis completo y minucioso de todos estos vocablos que contenga variantes y frecuencia de uso, que abarque los lenguajes de especialidad y proporcione propuestas didácticas. El número de vocablos semejantes en las dos lenguas con diferencias respecto a la sílaba tónica es bastante elevado especialmente en el área del lenguaje científico. Este es el motivo de que hayamos elegido el ámbito de las ciencias médicas para este artículo. Estas divergencias se deben en muchos casos a que la lengua portuguesa sigue la acentuación etimológica, pero la lengua española, por el contrario, se aparta de ella. El escritor, traductor y académico de la Lengua Valentín García Yebra (1999a, 1999b, 2003) atribuye a la influencia de la lengua francesa el cambio de acentuación en español. En una conferencia dictada en Bruxelas el 7 de junio de 1999 y publicada en la revista Terminologie et Traduction (GARCÍA YEBRA, 1999a) este autor analiza diferentes términos científicos que revelan esta alteración prosódica comparándolos con el portugués y el italiano como petroglifo, hematemesis o anestesia, y petróglifo, hematêmese y anestesia en español y portugués respectivamente. García Yebra (1999a, p. 182) llama a estos términos galicismos prosódicos y los define como "la palabra que, en vez de atenerse a las normas de acentuación española, basada en la cantidad larga o breve de la penúltima sílaba de la voz latina correspondiente, se acentúa de acuerdo con la voz francesa de su mismo origen" e ilustra su explicación con el siguiente ejemplo:

[...] es galicismo prosódico el nombre de una flor bien conocida: crisantemo, que procede del griego $\chi \rho v \sigma \alpha ́ v \theta \varepsilon \mu o v$ a través del latín chrysanthěmum o chrysanthěmon. La vocal de la penúltima sílaba de la palabra griega es una épsilon, es decir, una $e$ breve. Por eso se acentuaba en latín en la sílaba antepenúltima, como palabra esdrújula, coincidiendo en este caso con la acentuación griega. Según la norma prosódica, tendría que acentuarse en español como en latín; es decir crisántemo. ¿Por qué decimos, entonces, crisantemo? Porque en francés se acentúa la última sílaba pronunciada chrysanthème. [...] El portugués, en cambio, no sé si por estudio directo o por influjo británico, se muestra con frecuencia más atento a la norma latina, y así, en este caso, dice crisântemo, con acentuación etimológica. (GARCÍA YEBRA, 1999a, p. 182) 
Este factor que provoca una acentuación antietimológica en español es aplicable a un número importante de los términos relativos al ámbito de las ciencias de la salud que analizamos en este artículo.

\section{Bases teóricas para la elaboración de esta clasificación tipológica}

La enseñanza del léxico en el ámbito de la didáctica de lenguas extranjeras ha cobrado gran importancia en las últimas décadas, de ahí que diferentes estudios hayan centrado sus investigaciones en la búsqueda de nuevas líneas metodológicas para su enseñanza, como el enfoque léxico de Michael Lewis $(1993,1997)$ — que surge en los años 90 del siglo pasado como una evolución del enfoque comunicativo y del enfoque por tareas - y que establece la unidad léxica y los bloques prefabricados de palabras (chunks) como eje fundamental en la enseñanza de una lengua extranjera. El desarrollo de la competencia léxica se convierte así en un objetivo fundamental en el proceso de aprendizaje de una lengua, esto es, proporcionar información y estrategias necesarias para incrementar el número de unidades léxicas que forman el vocabulario interiorizado y activo de un hablante. En este sentido, diversas investigaciones revelan que la información léxica se almacena en la mente en redes flexibles e interconectadas (AITCHINSON, 1987; KIELHÖFER, 1994, CERVERO; PICHARDO, 2000). Por ello, para desarrollar la competencia léxica los estudios sobre adquisición del léxico coinciden en señalar las ventajas de realizar asociaciones de unidades léxicas que faciliten la asimilación del vocabulario y su posterior recuperación para su uso adecuado (MORANTE VALLEJO, 2005; HIGUERAS, 2004, 2017; BARALO, 2007). Como afirma Marta Baralo (2007, p. 397) las actividades para el aprendizaje del léxico deberían

favorecer las estrategias de asociación de piezas léxicas a través de sus redes, como las asociaciones morfológicas (derivación y composición); semánticas (hiponimia e hiperonimia; sinonimia y antonimia; polisemia; campos semánticos y asociativos); léxicas (cognados, expresiones idiomáticas); discursivas (conectores textuales, género) y pragmáticas (selección léxica condicionada por las variables de la situación de comunicación).

Mediante estrategias de relación asociativa proporcionamos en este artículo una selección de falsos amigos prosódicos clasificados por criterios morfológicos y semánticos. Es una compilación léxica que puede ser de utilidad para la elaboración de tareas didácticas específicas orientadas a desarrollar la competencia léxica y evitar interferencias prosódicas en la comprensión y la producción oral entre el portugués y español en el ámbito de las ciencias 
médicas. La clasificación morfológica proporciona información para trabajar aspectos relacionados con la categoría gramatical o con la formación de palabras (derivación y composición). En este trabajo los vocablos heterotónicos se distribuyen en diferentes grupos según los afijos o elementos compositivos con los que se forman como pueden ser palabras formadas con el elemento -algia como mialgia y dorsalgia en español respecto a las palabras mialgia y dorsalgia en portugués, o palabras creadas con el elemento compositivo -dermia como esclerodermia y ocrodermia en español respecto a esclerodermia y ocrodermia en potugués. Son redes asociativas que permiten relacionar cada afijo con su significado y la tonicidad en español y en portugués; desarrollan la conciencia morfológica del discente y favorecen el proceso de adquisición léxica desde la fase de reconocimiento y almacenamiento en la memoria hasta la fase de producción. En el bloque semántico los heterotónicos se distribuyen en campos léxicos. En este caso se trata de vocablos relativos al área de la salud distribuidos en diferentes disciplinas y subdisciplinas como anatomía y fisiología, genética, cirugía, cardiología o patología.

La enseñanza de los heterotónicos debe seguir una metodología similar a la de la enseñanza del léxico en general. Estos términos aparecerán contextualizados e integrados en el conjunto del vocabulario previsto para la enseñanza de una determinada materia. Para facilitar su memorización y adquisición, se realizarán actividades que ayuden a practicar y asimilar la prosodia contrastiva junto con los demás componentes del lenguaje. Como señala Vivanco respecto a las estrategias de aprendizaje para memorizar el vocabulario "los engranajes asociativos de la memoria son personales, y, por tanto, complejos: así, cada alumno desarrollará técnicas específicas y personalizadas para memorizar una palabra que serán efectivas sólo para él de acuerdo a su bagaje cultural, intelectual, afectivo y experiencial" (VIVANCO, 2001, p. 180). En el caso que nos ocupa, dada la especificidad terminológica, los usuarios serán probablemente especialistas o conocedores de alguna rama de la medicina por lo que sus intereses y el conocimiento temático del área de la salud favorecerán el procesamiento de la información, su memorización y su posterior recuperación.

\section{Clasificación de heterotónicos del ámbito de la salud en el portugués de Brasil y el español peninsular}

En el documento anexo de este artículo presentamos dos bloques de falsos amigos prosódicos: uno organizado desde el punto de vista morfológico y otro desde el punto de vista 
semántico. Las palabras de la lengua portuguesa figuran en letra cursiva y las de la lengua española en redonda. Algunos términos como álcool, cérebro o terapia pertenecen al lenguaje común, pero la mayoría se vincula al lenguaje especializado y se engloban por tanto en los niveles C1 y C2 del Marco Común Europeo de Referencia para las Lenguas (CONSEJO DE EUROPA, 2002). La sílaba tónica de cada vocablo se destaca en negrita (trombocito, en español y trombócito en portugués) y cuando existen dos variantes ortográficas o prosódicas de una palabra se separan por una barra como sucede en psicópata/sicópata o alvéolo/alveolo. Las variantes prosódicas son vocablos que tienen más de una acentuación prosódica en una de las dos lenguas, una divergente y otra coincidente en portugués y en español, por consiguiente solo la forma divergente será un vocablo heterotónico. Esta doble tonicidad está condicionada por factores diatópicos, diastráticos o diafásicos de la lengua. En el ejemplo anterior, la forma esdrújula 'alvéolo', coincidente con el portugués (alvéolo), es la más cercana a la etimología y la preferida en el uso culto, pero también se usa con frecuencia en español, y es válida, la forma llana alveolo. Por lo tanto, en este caso la forma llana 'alveolo' es a que podemos catalogar como falso amigo prosódico respecto al portugués alvéolo. En estos casos, colocamos en primer lugar la forma recomendada por las fuentes consultadas como variante principal o de mayor frecuencia de uso. Cuando no disponemos de información sobre recomendaciones de uso, consideramos variante secundaria la que remite a otra variante principal, que es la que registra toda la información pertinente en el diccionario. Por ejemplo: clitóris/clítoris. Una búsqueda en el diccionario Houaiss de la forma clítoris remite a clitóris y esta última forma contiene la definición en el diccionario. Algunos de estos términos biacentuales no son realmente heterotónicos en el uso común de la lengua, dado que la forma más usada coincide en español y en portugués. Es el caso de palabras como biópsialbiopsia o hematúria/hematuria ya que las formas consagradas por el uso en portugués son biópsia y hematúria y coinciden con el español biopsia y hematuria. De todos modos, hemos optado por incluirlos en este trabajo porque los factores que determinan los criterios de uso para emplear una forma u otra en casos de variantes prosódicas, no siempre están bien definidos. Es un asunto complejo que requiere un estudio específico.

En el bloque de redes morfológicas los términos heterotónicos están distribuidos por grupos según los afijos que lo forman. Esta clasificación favorece el procesamiento de la información y permite relacionar la forma de un elemento compositivo con su significado y su tonicidad. Las actividades didácticas con estos elementos compositivos son muy útiles para desarrollar la conciencia morfológica y facilitar la producción escrita y oral. Los principales afijos y elementos compositivos de la lengua española usados en la terminología médica que 
presentan diferente tonicidad respecto al portugués son: -algia, -astenia, -cardia, -cito, dermia, -ectasia, -emia, -estesia, -fagia, -fasia, -fobia, -frenia, -genesia, -genia, -glosia, gnosia, -iaco/íaco, -lalia, -lexia, -malacia, -megalia, -pata, -pedia, -penia, -pepsia, -pexia, plasia, -plastia/plastía, -plejia/plejía, -rragia, -scopia/scopía, -terapia, -termia, -timia y -trofia.

Los falsos amigos en el bloque de redes semánticas se distribuyen por orden alfabético en 21 grupos temáticos: anatomía y fisiología; bioquímica; cardiología; cirugía; citología, histología y embriología; dermatología; diagnóstico y terapéutica; digestivo y hepatología; endocrinología, metabolismo e inmunología; farmacología; genética; ginecología; neumología; neurología; odontología y estomatología; oftalmología; otorrinolaringología; patología general; patología infecciosa; psicología y psiquiatría; y traumatología y reumatología. En ocasiones un mismo término aparece en más de un bloque como sucede con 'estrógeno', que se encuentra en en "anatomía y fisiología" y en "bioquímica". La mayoría de estos términos están interconectados y podrían incluirse en varios grupos. Esta división en disciplinas y subdisciplinas es una estrategia para desglosar el conjunto de vocablos en pequeños bloques para facilitar su adquisición. Por último, cuando registramos variantes de un mismo concepto como 'colpoplastia' y 'vaginoplastia', o 'amiotrofia' y 'atrofia muscular' cada término aparece en su lugar correspondiente por orden alfabético.

En este artículo, dada la confusión que podría generar tratar al mismo tiempo todas las variantes de la lengua portuguesa y española, nos centramos únicamente en la variedad del portugués de Brasil respecto al español de España, si bien en el bloque de elementos morfológicos indicamos en nota a pie de página algunas aclaraciones relacionadas con diferencias de tonicidad de algunos sufijos o elementos compositivos respecto al portugués de Portugal o al español de América.

Las fuentes de documentación consultadas para elaborar este trabajo han sido las siguientes: para la lengua española hemos consultado el "Diccionario de la Real Academia española" (DRAE) (RAE; ASALE, 2014), versión electrónica de la vigesimotercera edición de este diccionario y el "Diccionario Panhispánico de dudas" (DPD) (RAE; ASALE, 2005). Para la lengua portuguesa (portugués de Brasil) usamos el "Dicionário Houaiss da Língua Portuguesa" (DH) (HOUAISS, 2009) y el "Vocabulário Ortográfico da Língua Portuguesa" (VOLP) (ABL, 2009) de la Academia Brasileira de letras. Hemos consultado también dos diccionarios especializados en terminología médica: para el español, el "Diccionario médicobiológico, histórico y etimológico" (CORTÉS GABAUDÁN, 2007-2018) coordinado por el profesor Francisco Cortés Gabaudán de la Universidad de Salamanca, y para el portugués el "Compacto dicionário ilustrado de saúde" de Carlos de Roberto Lyra da Silva (2007). 


\section{Consideraciones finales}

En el presente trabajo hemos analizado falsos amigos prosódicos en portugués y español entendiendo por ello vocablos iguales o semejantes tanto en la forma como en el significado que presentan la sílaba tónica en una posición distinta en cada lengua, y para ello hemos confeccionado un corpus de 555 heterotónicos, todos ellos pertenecientes al ámbito de la medicina. El análisis realizado nos ha permitido elaborar una clasificación en la que el vocabulario se presenta de forma sistematizada a nivel morfológico y semántico. Por lo que respecta a los primeros, partiendo de un corpus de 316 vocablos, hemos analizado y sistematizado aquellos elementos compositivos, fundamentalmente sufijos, que pueden inducir a error a los alumnos de portugués como lengua extranjera. Gracias al sistema confeccionado de redes morfológicas se puede comprobar la diferente acentuación de vocablos en portugués y en español, y evitar las interferencias que pueden producirse al usar estas palabras. La clasificación morfológica ayuda a procesar la información y tomar conciencia de la relación existente entre la morfología, el significado y la posición acentual. Por lo que respecta a los falsos amigos semánticos hemos analizado 429 vocablos relativos al área de la salud distribuidos en diferentes campos léxicos como anatomía y físiología, genética, cirugía, cardiología o patología. Esta distribución permite al alumno asimilar de forma organizada el vocabulario médico susceptible de generar errores prosódicos ya que los vocablos se distribuyen en disciplinas y subdisciplinas médicas. Con esta clasificación el alumno puede realizar asociaciones semánticas y trabajar de forma individualizada las diferentes áreas temáticas desglosadas en el corpus. Las actividades didácticas elaboradas con la clasificación propuesta posibilitan el desarrollo de la conciencia morfológica y semántica, y facilitan la producción escrita y oral.

El análisis realizado pone de manifiesto el elevadísimo número de heterotónicos existentes en el lenguaje médico y la utilidad de realizar redes asociativas como estrategia didáctica para desarrollar la competencia léxica. Entendemos que la clasificación de heterotónicos elaborada, siguiendo diferentes estrategias de asociación léxica, es de gran utilidad como fuente lexicográfica para la didáctica del portugués para fines específicos.

\section{REFERÊNCIAS}

\section{ACADEMIA BRASILEIRA DE LETRAS. Vocabulário Ortográfico da Língua}

Portuguesa. 5 ed. São Paulo: Global Editora, 2009. Disponible en:

<http://www.academia.org.br/nossa-lingua/busca-no-vocabulario>. Acceso el: 25 jul. 2018. 
AITCHISON, J. Words in the mind: an introduction to the mental lexicon. Oxford: Basil Blackwell, 1987.

ALVES, L. Mena. Uma discussão sobre o acento em português e em espanhol. In: $5^{\circ}$ Encontro do Celsul, Curitiba-PR, 2003. Anais... Curitiba-PR, 2003. p. 749-754. Disponible en <http://linguistica.fflch.usp.br/sites/linguistica.fflch.usp.br/files/acento\%20ptg,\%20esp.pdf>. Acceso el: 20 jul. 2018.

ANDRADE NETA, N. F. Aprender español es fácil porque hablo portugués: ventajas y desventajas de los brasileños para aprender español. Cuadernos Cervantes de la Lengua Española, n. 29, p. 46-55, 2000. Disponible en:

$<$ https://dialnet.unirioja.es/servlet/articulo?codigo=187136>. Acceso el: 2 jun. 2018

BARALO, M. Adquisición de palabras: redes semánticas y léxicas. In: Foro de español internacional: Aprender y enseñar léxico, Múnich 2007. Actas del programa de formación para el profesorado de Múnich, 2006-2007. Múnich: Instituto Cervantes, 2007. Disponible en:

$<$ https://cvc.cervantes.es/ensenanza/biblioteca_ele/publicaciones_centros/PDF/munich_20062007/04_baralo.pdf>. Acceso el: 2 jun. 2018.

BECKER, I. Manual de espanhol. São Paulo: Companhia Editora Nacional, 1945.

BENEDETTI, A. M. El portugués y el español frente a frente: aspectos fonético-fonológicos y morfosintácticos. Carabela, v. 51, p. 147-171, 2002.

BRAGA, L. A.; DURÃO, A. B. A. B. A questão da heterotonicidade na relação portuguêsespanhol. In: DURÃO A. B. A. B; ANDRADE, O. G. Problemas de Ensino/Aprendizagem de Brasileiros Estudantes de Espanhol, Tomo I. Londrina: Editora UEL, 2000. p. 95-99.

CARLUCCI, L.; DÍAZ Ferrero, A. M. Falsas equivalencias en la traducción de lenguas afines: propuesta taxonómica. Sendebar, n. 18, p. 159-191, 2007.

CERVERO, M. J; PICHARDO F. Aprender y enseñar vocabulario. Madrid: Edelsa, 2000.

CONSEJO DE EUROPA. Marco Común Europeo de Referencia para las Lenguas:

aprendizaje, enseñanza, evaluación. Madrid: Ministerio de Educación, Cultura y Deporte, 2002. Disponible en: 〈https://cvc.cervantes.es/ensenanza/biblioteca_ele/marco/cvc_mer.pdf >. Acceso el: 26 jul. 2018.

CORTÉS GABAUDAN, F. (coord.). Diccionario médico-biológico, histórico y etimológico (Dicciomed.eusal.es). Salamanca: Ediciones Universidad de Salamanca, 20072018. Disponible en: 〈http://dicciomed.eusal.es〉. Acceso el: 24 jul. 2018.

DÍAZ FERRERO, A. M. Falsos amigos Portugués-Español. Español-Portugués. Lisboa: Lidel editora, 2013.

DÍAZ ROJO, J. A. Nociones de neología. Panacea, 2000. v. 1, n. 2, p. 55-56. 
DÍAZ Y GARCÍA TALAVERA, M. Dicionário Santillana para estudantes: Espanhol/Português-Português/Espanhol. São Paulo: Editora Santillana, 2008.

DUARTE, C. A. Diferencias de usos gramaticales entre español-portugués, Madrid: Edinumen, 1999.

GARCÍA YEBRA, V. Influencia del francés en nuestro vocabulario científico. In: Conferencia dictada los días 7 y 8 de junio de 1999 en Bruselas y Luxemburgo, respectivamente. Terminologie et Traduction, n. 1, 1999a, p. 182-194. Disponible en $<$ http://ec.europa.eu/translation/bulletins/puntoycoma/58/vgyebra.pdf>. Acceso el: 15 jul. 2018.

GARCÍA YEBRA, V. Diccionario de galicismos prosódicos y morfológicos. Madrid: Gredos, 1999b.

GARCÍA YEBRA, V. Cien borrones prosódicos en la terminología científica española. Panacea, n. 12, p. 160-161, 2003. Disponible en:

<http://www.tremedica.org/panacea/IndiceGeneral/n12_tribuna_GYebra.pdf>. Acceso el: 25 jul. 2018.

HIGUERAS, M. Claves prácticas para la enseñanza del léxico. Carabela, 56, p. 5-25, 2004.

HIGUERAS, M. Logros y retos de la enseñanza del léxico. Enseñar léxico en el aula de español: El poder de las palabras. Barcelona: Difusión, 2017, p. 15-23.

HOUAISS, A.; VILLAR, M. de S. Dicionário Houaiss da língua portuguesa. Río de Janeiro: Objetiva, 2009.

KIELHÖFER, B. Wörter lernen, behalten und erinnern. Neusprachliche Mitteilingen, v. 4,1994. p. 211-220.

LEWIS, M. The lexical approach. The State of ELT and a Way Forward. Londres: Teacher Training, 1993.

LEWIS, M. Implementing the Lexical Approach. Putting Theory into Practice. Londres: Teacher Training, 1997.

MARRONE, C. S. Português-espanhol: aspectos comparativos. São Paulo: Editora do Brasil, 1990.

MASIP, V. Armadilhas da língua espanhola: "falsos amigos", convergências, divergências, ambiguidades e equívocos. Recife: Edufpe, 2013.

MILANI, E. M. Gramática de espanhol para brasileiros. 1ª ed. São Paulo: Saraiva, 1999.

MINIDICIONÁRIO SARAIVA: Espanhol-Português; Português-Espanhol. 8 ed. São Paulo: Saraiva, 2013.

MORANTE VALLEJO, R. El desarrollo del conocimiento léxico en segundas lenguas, Madrid: Arco Libros, 2005 
MORENO, C.; ERES FERNÁNDEZ, G. Gramática contrastiva del español para brasileños, Madrid: Sgel, 2007.

NASCENTES, Antenor. Esbozo de comparación del español con el portugués. Santiago: Prensas de la Universidad de Chile, 1936.

REAL ACADEMIA ESPAÑOLA Y ASOCIACIÓN DE ACADEMIAS DE LA LENGUA ESPAÑOLA. Diccionario panhispánico de dudas. Madrid: Santillana, 2005. Disponible en <http://www.rae.es/recursos/diccionarios/dpd>. Acceso el: 25 jul. 2018.

REAL ACADEMIA ESPAÑOLA; ASOCIACIÓN DE ACADEMIAS DE LA LENGUA ESPAÑOLA. Diccionario de la lengua española, 23. ${ }^{a}$ edición. Madrid: Espasa, 2014. Disponible en: < http://www.rae.es/>. Acceso el: 26 jul. 2018.

SANTAMARÍA B. E. Enseñar prosodia en el aula: Reflexiones y propuestas. Las destrezas orales en la enseñanza del español L2-LE (XVII Congreso Internacional de la Asociación del Español como lengua extranjera (ASELE): Logroño 27-30 de sept. de 2006). Logroño: Universidad de la Rioja, v. 2, p. 1237-1250, 2007.

SERRA, M. L.; BERTELEGNI, M. C.; ABREU, R. M. M. Fonética aplicada a la enseñanza del español como lengua extranjera: un curso para lusófonos. São Paulo: Editorial Galpão, 2007.

SILVA, C. R. L.; SILVA, R. C. L.; VIANA, D. L. Compacto dicionário ilustrado de saúde. 2. ed. São Caetano do Sul-SP: Yendis editora, 2007. Disponible en:

<http://www.mkmouse.com.br/livros/Dicionario_Ilustrado_de_Saude.pdf >. Acceso el: 25 jul. 2018.

SILVEIRA, M. S. O estudo dos heterogenéricos, heterossemânticos e heterotônicos como aceleradores do processo ensino-aprendizagem do idioma espanhol para os acadêmicos de um curso de Letras. Revista do Sell, v. 1, n. 1, 2008. Disponible en

<http://seer.uftm.edu.br/revistaeletronica/index.php/sell/article/view/22/29>. Acceso el: $10 \mathrm{de}$ maio 2018.

VIVANCO, V. La adquisición de vocabulario en una segunda lengua: estrategias cognitivas y lazos afectivos. In: Encuentro Revista de investigación e innovación en la clase de idioma, v. 12, p. 177-187, 2001.

VOLPI, M. T. DELP- Palabras \& Palavras. 2 ed. Porto Alegre: Rígel, 2005.

\section{Como referenciar este artigo}

DÍAZ FERRERO, Ana María. Falsos amigos prosódicos entre la lengua portuguesa y la española en el ámbito de las ciencias de la salud. Rev. EntreLínguas, Araraquara, v. 4, n. 2, p. 182-204, jul./dez., 2018. E-ISSN: 2447-3529. DOI: 10.29051/rel.unesp.v4.n2.2018.11605

Submetido em: 28/07/2018

Aprovado em: 04/11/2018 


\section{ANEXO}

Anexo 1 - Bloque 1 - Redes morfológicas

\section{ESPAÑOL $\quad$ PORTUGUÉS}

-algia: dolor (del griego - $\alpha \lambda \gamma i ́ \alpha$ : 'dolor'). Forma del afijo en portugués: -algia. artralgia, cardialgia, cefalalgia, cistalgia, coxalgia, dorsalgia, enteralgia, epigastralgia, fibromialgia, gastralgia, lumbalgia, metralgia, mialgia, neuralgia, odontalgia, otalgia, proctalgia, sacralgia... cistalgia, coxalgia, dorsalgia, enteralgia, epigastralgia, fibromialgia, gastralgia, lombalgia, metralgia, mialgia, nevralgia/neuralgia, odontalgia, otalgia, proctalgia, sacralgia...

-astenia: debilidad, cansancio, fatiga (del griego d’: 'sin, no'; $\sigma \theta \varepsilon \dot{v} v o \varsigma$ : 'vigor, fuerza'). Forma del afijo en portugués: -astenia.

\begin{tabular}{|l|lr|}
\hline $\begin{array}{l}\text { astenia, calistenia, ergastenia, } \\
\text { fonastenia, miastenia, } \\
\text { psicastenia... }\end{array}$ & $\begin{array}{r}\text { astenia, calistenia, ergastenia, } \\
\text { neurastenia, }\end{array}$ & $\begin{array}{l}\text { fonastenia, miastenia, neurastenia, } \\
\text { psicastenia... }\end{array}$
\end{tabular}

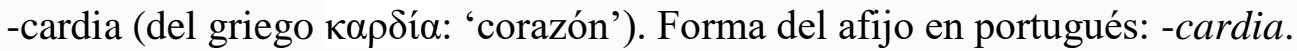

Esta raíz griega está presente también en el afijo cardio en español y en portugués, pero no se incluyen en este trabajo porque la tonicidad coincide en ambas lenguas. Ejemplos: cardiología y miocardio en español; cardiologia y miocardio en portugués. atelocardia, bradicardia, braquicardia, dexiocardia, ectocardia, estenocardia, miocardia, taquicardia...

\begin{tabular}{|c|c|}
\hline $\begin{array}{r}\text { baticardia, } \\
\text { dexiocardia, } \\
\text { miocardia, }\end{array}$ & \begin{tabular}{l}
\multicolumn{2}{c}{ atelocardia, } & baticardia, \\
bradicardia, braquicardia, dexiocardia, \\
ectocardia, estenocardia, \\
taquicardia...
\end{tabular} \\
\hline
\end{tabular}

-cito: célula (del griego: $\kappa$ cos: 'célula'). Forma del afijo en portugués: -cito. adipocito, agranulocito, astrocito, coanocito, condrocito, epicito, eritrocito, espermatocito, fagocito, fibrocito, gametocito, granulocito, hepatocito, histiocito, leucocito, linfocito, mastocito, melanocito, monocito, neocito, oocito, osteocito, ovocito, reticulocito, trombocito... adipócito, agranulócito, astrócito, coanócito, condrócito, epícito, eritrócito, espermatócito, fagócito, fibrócito, gametócito, granulócito, hepatócito, histiócito, leucócito, linfócito, mastócito, melanócito, monócito, neócito, oócito, osteócito, ovócito, reticulócito, trombócito...

-dermia: piel (del griego $\delta \varepsilon \rho \mu i ́ \alpha:$ 'piel'). Forma del afijo en portugués: -dermia.

Los afijos dermato y dermo tienen la misma raíz, pero no se incluyen en este artículo porque la tonicidad coincide en español y en portugués. Ejemplos: dermatología y ectodermo en español; dermatologia y ectoderma en portugués.

\begin{tabular}{|rr|lr|}
\hline \multicolumn{2}{|c|}{ anetodermia, } & bromodermia, \\
cianodermia, & $\begin{array}{r}\text { anetodermia, } \\
\text { esclerodermia, }\end{array}$ & $\begin{array}{r}\text { cianodermia, esclerodermia, } \\
\text { leucodermia, } \\
\text { ocrodermia, piodermia, xantodermia... }\end{array}$ & $\begin{array}{l}\text { leucodermia, linfodermia, liodermia, } \\
\text { ocrodermia, piodermia, xantodermia... }\end{array}$ \\
\hline
\end{tabular}




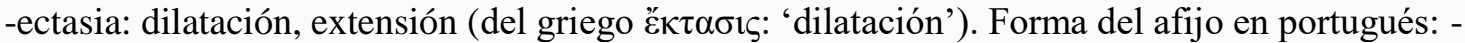
ectasia.

angiectasia, atelectasia,

bronquiectasia, corectasia, gastrectasia, telangiectasia, tiflectasia... angiectasia,

atelectasia,

bronquiectasia, corectasia, gastrectasia, telangiectasia, tiflectasia...

-emia: sangre (del griego - $\alpha \mu$ ía: 'sangre'). Forma del afijo en portugués: -emia.

$$
\text { acetonemia, acidemia, } \quad \text { acetonemia, acidemia, alcoolemia, }
$$

alcoholemia, anoxemia, bacilemia, anoxemia, bacilemia, bacteriemia,

bacteriemia, colesterolemia, colesterolemia, dislipidemia, eritremia,

dislipidemia, eritremia, glucemia ${ }^{2}$, glicemia, hiperemia, leucemia, lipemia,

hiperemia, leucemia, lipemia, oligocitemia, piemia, potassemia,

oligocitemia, piemia, potasemia, septicemia, talassemia, uremia, viremia,

septicemia, talasemia, uremia, viremia, volemia...

volemia...

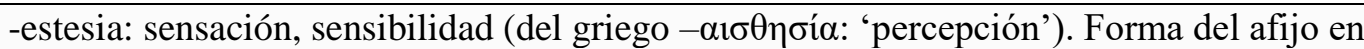
portugués: -estesia.

anestesia, cenestesia, cinestesia, anestesia, cenestesia, cinestesia,

crianestesia, disestesia, hiperestesia, crianestesia, disestesia, hiperestesia,

\begin{tabular}{l|l} 
hipoestesia, parestesia, sinestesia... & hipoestesia, parestesia, sinestesia...
\end{tabular}

-fagia: comer (del griego payía: 'acción de comer'). Forma del afijo en portugués: -fagia.

El afijo fago tiene la misma raíz y está presente en palabras como macrófago o eritrófago en español y macrófago o eritrófago en portugués. La tonicidad en estos casos coincide en ambas lenguas.

$$
\text { aerofagia, afagia, autofagia, aerofagia, afagia, autofagia, }
$$

bradifagia, coprofagia, disfagia, geofagia, bradifagia, coprofagia, disfagia, geofagia,

odinofagia, onicofagia, taquifagia...

odinofagia, onicofagia, taquifagia...

-fasia: habla, lenguaje (del griego $\alpha$ : 'no, sin’ $+\varphi \alpha-[\varphi \eta \mu$ í] 'decir, hablar'). Forma del afijo en

\begin{tabular}{|c|c|}
\hline $\begin{array}{l}\text { acatafasia, afasia, agitofasia } \\
\text { ifasia, catafasia, } \\
\text { izofasia, parafasia... }\end{array}$ & $\begin{array}{l}\text { acatafasia, afasia, } \\
\text { bradifasia, catafasia, } \\
\text { esquizofasia, parafasia... }\end{array}$ \\
\hline
\end{tabular}
portugués: -fasia.

-fobia: temor, miedo (del griego fobia.

aerofobia, androfobia, agorafobia, aerofobia, androfobia, agorafobia,

amaxofobia, antropofobia, aracnofobia, amaxofobia, antropofobia, aracnofobia,

ciberfobia, cinofobia, claustrofobia, ciberfobia, cinofobia, claustrofobia,

demofobia, entomofobia, fotofobia, demofobia, entomofobia, fotofobia,

homofobia, lalofobia, necrofobia, homofobia, lalofobia, necrofobia, teofobia,

teofobia, tremofobia, xenofobia...

tremofobia, xenofobia...

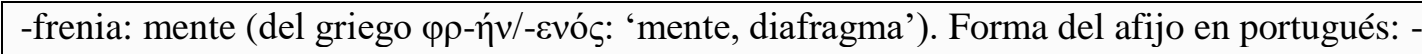
frenia.

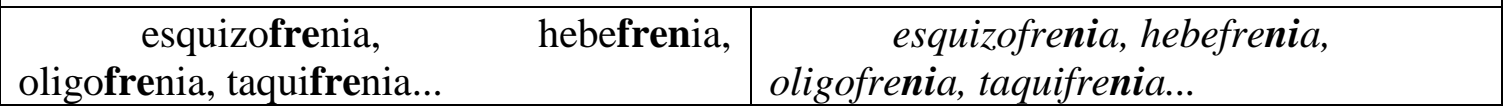

${ }^{2}$ Como informa el $D P D$ en amplias zonas de América es mayoritaria la forma 'glicemia'.

Rev. EntreLínguas, Araraquara, Araraquara, v. 4, n. 2, p. 182-204, jul./dez., 2018. 


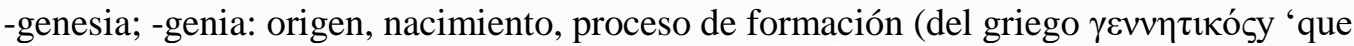

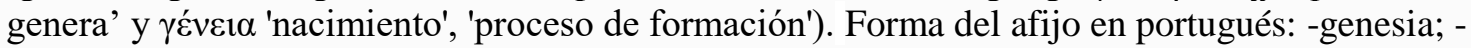
genia.

Las formas -génesis, -genesia, y -genia son tres variantes compositivas usadas en la terminología médica con un significado similar. Como afirma Díaz Rojo (2000, p. 55) dada la sinonimia de estas formas, podrían adjuntarse indistintamente para formar términos médicos, aunque en casi todos los casos existen ciertas preferencias más o menos consolidadas. agenesia, disgenesia, eugenesia... $\quad$ agenesia, disgenesia, eugenesia... embriogenia, etiopatogenia, embriogenia, etiopatogenia, patogenia, patogenia, piogenia, nosogenia, piogenia, nosogenia, ontogenia... ontogenia...

-glosia: lengua (del griego $\gamma \lambda \tilde{\omega} \sigma \sigma \alpha$ 'lengua'). Forma del afijo en portugués: -glossia. aglosia, bariglosia, macroglosia, aglossia, bariglossia, macroglossia, microglosia, tricoglosia... microglossia, tricoglossia...

-gnosia: conocimiento, percepción (del griego $\gamma \nu \omega$ - $[\gamma \iota \gamma v \omega ́ \sigma \kappa \omega]$ 'conocer'). Forma del afijo en portugués: -gnosia.

agnosia,

astereognosia,

fonagnosia, prosopagnosia... anosognosia, $\quad$ agnosia, anosognosia, astereognosia,

farmacognosia, farmacognosia, fonagnosia, prosopagnosia...

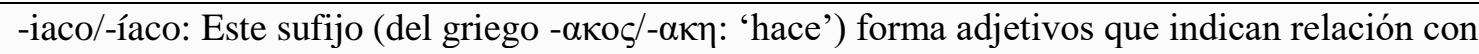
lo designado por el sustantivo base. Ejemplo: cardiaco/cardíaco: relativo a cardio (corazón). Ambas acentuaciones (-iaco e -íaco) son correctas. Según el $D P D$ en el español de España es más común la pronunciación llana (celiaco, cardiaco, afrodisiaco...), y en el español de América la norma culta prefiere la forma con acento en la í (celíaco, cardíaco, afrodisíaco...). Forma del afijo en portugués: -íaco. afrodisiaco/afrodisíaco, cardiaco/cardíaco, celiaco/celíaco, hipocondriaco/hipocondríaco, iliaco/ilíaco, maniaco/maníaco... afrodisíaco, cardíaco, celíaco, hipocondríaco, ilíaco, maníaco...

-lalia: hablar (del griego $\lambda \alpha \lambda \imath$ ó 'charla'). Forma del afijo en portugués: -lalia.

alalia, bradilalia, dislalia, ecolalia, $\quad$ alalia, bradilalia, dislalia, ecolalia, glosolalia, neolalia, palilalia, paralalia, glossolalia, neolalia, palilalia, paralalia, rinolalia, taquilalia... rinolalia, taquilalia...

-malacia: ablandamiento (del griego $\mu \alpha \lambda \alpha \kappa i ́ \alpha$ 'reblandecimiento'). Forma del afijo en portugués: -malacia.

cardiomalacia, encefalomalacia, gastromalacia, mielomalacia, miomalacia, onicomalacia, queratomalacia osteomalacia,

\section{cardiomalacia, encefalomalacia,} gastromalacia, mielomalacia, miomalacia, onicomalacia, osteomalacia, ceratomalacialqueratomalacia...

-megalia: agrandamiento, tamaño excesivo (del griego $\mu \varepsilon \gamma \alpha \lambda$-ía 'tamaño excesivo'). Forma del afijo en portugués: -megalia.

\begin{tabular}{|lr|lr|}
\hline \multicolumn{1}{|c}{ acromegalia, } & $\begin{array}{r}\text { adenomegalia, } \\
\text { cardiomegalia, } \\
\text { esplenomegalia, } \\
\text { hepatomegalia... }\end{array}$ & $\begin{array}{r}\text { acromegalia, } \\
\text { gastromegalia, }\end{array}$ & $\begin{array}{r}\text { adenomegalia, } \\
\text { citomegalia, } \\
\text { cardiomegalia, } \\
\text { esplenomegalia, } \\
\text { hepatomegalia... }\end{array}$
\end{tabular}




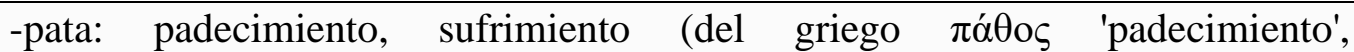
'sentimiento'). Forma del afijo en portugués: -pata. En portugués las palabras formadas con este sufijo tienen doble prosodia. Como señala el $D H$ la forma predominante es la llana (alopata, neuropata...)

Los sufijos - patía, en español, y -patia, en portugués, tienen la misma raíz y se emplean generalmente para crear sustantivos que designan padecimiento o enfermedad como cardiopatía, osteopatía o neuropatía y cardiopatia, osteopatia e neuropatia en español y portugués respectivamente. La sílaba tónica en estos casos coincide en ambas lenguas.

\begin{tabular}{|c|c|}
\hline $\begin{array}{l}\text { alópata, cardiópata, } \\
\text { naturópata, } \\
\text { psicópata,... }\end{array}$ & $\begin{array}{l}\text { alopata/alópata, cardiopata/cardiópata } \\
\text { hemeopata/homeópata, } \\
\text { naturopata/naturópata neuropata/neurópata, } \\
\text { osteopata/osteópata, psicopata/psicópata... }\end{array}$ \\
\hline
\end{tabular}

-penia: carencia, disminución (del griego $\pi \varepsilon v i ́ \alpha$ 'carencia', 'pobreza'). Forma del afijo en portugués: -penia.

calcipenia, eritropenia, leucopenia, calcipenia, eritropenia, leucopenia,

linfopenia, neutropenia, pancitopenia, linfopenia, neutropenia, pancitopenia,

trombocitopenia, trombopenia... trombocitopenia, trombopenia...

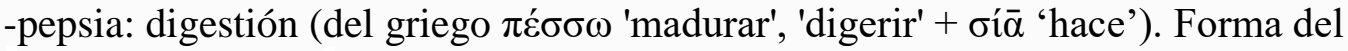
afijo en portugués: -pepsia. eupepsia...

apepsia, bradipepsia, dispepsia, apepsia, bradipepsia, dispepsia, eupepsia..

-pexia: fijación (del griego $\pi \eta \xi \xi i ́ \alpha$ 'fijación quirúrgica'). Forma del afijo en portugués: pexia.

cantopexia

cistopexia, cantopexia, cistopexia, colpopexia,

colpopexia, gastropexia, ligamentopexia, gastropexia, ligamentopexia, mastopexia,

mastopexia, nefropexia... nefropexia...

-plasia: formación, desarrollo (del griego - $\pi \lambda \alpha \sigma i ́ \alpha$ 'formación celular'). Forma del afijo en portugués: -plasia.

anaplasia, aplasia, desmoplasia, anaplasia, aplasia, desmoplasia, displasia,

displasia, fibroplasia, hiperplasia, fibroplasia, hiperplasia, hipocondroplasia,

hipocondroplasia, hipoplasia, leucoplasia, hipoplasia, leucoplasia, metaplasia,

metaplasia, mielodisplasia, neoplasia...

mielodisplasia, neoplasia...

-plastia/-plastía: corrección, reparación quirúrgica (del griego $-\pi \lambda \alpha \sigma \tau i ́ \alpha$ 'remodelación quirúrgica'). Forma del afijo en portugués: -plastia.

Ambas acentuaciones (-plastia y -plastía) son válidas en español. Como informa el $D P D$ en el uso culto mayoritario predominan las formas con diptongo (angioplastia, mamoplastia, rinoplastia, etc.), pero en algunas zonas de América son normales las formas con hiato (angioplastía, mamoplastía, rinoplastía, etc.).

blefaroplastia, heteroplastia, blefaroplastia, heteroplastia, mamoplastia, otoplastia, queiloplastia, mamoplastia, otoplastia, queiloplastia, quiroplastia, rinoplastia... quiroplastia, rinoplastia... 
-plejia/-plejía: parálisis (del griego $-\pi \lambda \eta \xi i ́ \alpha$ 'ataque paralizante'). Forma del afijo en portugués: -plegia.

Como indica el DPD, en español las palabras con esta terminación, salvo apoplejía, tienen dos acentuaciones válidas: una con hiato entre las dos vocales finales, acorde con la pronunciación griega (hemiplejía, paraplejía, etc.), y otra con diptongo, acorde con la pronunciación latina (hemiplejia, paraplejia, etc.). En el español actual son más frecuentes las formas en -plejia.

glosoplejia/glosoplejía,

hemiplejia/hemiplejía,

oftalmoplejia/oftalmoplejía,

paraplejia/paraplejía,

tetraplejia/tetraplejía... glossoplegia, hemiplegia, oftalmoplegia, paraplegia, tetraplegia...

-rragia: derrame (del griego $\rho \rho \alpha \gamma i ́ \alpha$ 'flujo violento'). Forma del afijo en portugués: -rragia.

broncorragia, hemorragia, $\quad$ broncorragia, hemorragia, menorragia,

menorragia, metrorragia, otorragia, metrorragia, otorragia, rinorragia...

rinorragia...

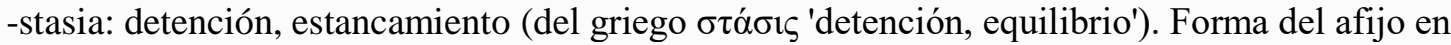
portugués: -stasia

amiostasia, enterostasia, amiostasia, enterostasia, hemostasia,

hemostasia, menostasia... menostasia...

-scopia/scopía: visualización, examen o inspección con instrumentos ópticos (del griego бколía 'inspección', 'examen visual'). Forma del afijo en portugués: -scopia.

Como indica el DPD el elemento compositivo -scopia/scopía tiene dos acentuaciones válidas. Las formas con diptongo (-ia), acordes con la pronunciación latina, son las preferidas en España (amnioscopia, endoscopia, laparoscopia...), y las formas con hiato (-ía), acordes con la pronunciación etimológica griega, suelen ser las preferidas en el español americano (amnioscopía, endoscopía, laparoscopía...). amnioscopia, artroscopia, amnioscopia, artroscopia, bacterioscopia, broncoscopia, cistoscopia, bacterioscopia, broncoscopia, colonoscopia, dactiloscopia, endoscopia, cistoscopia, colonoscopia, dactiloscopia, gastroscopia, laparoscopia, laringoscopia, endoscopia, gastroscopia, laparoscopia, microscopia, oftalmoscopia, otoscopia, laringoscopia, microscopia, radioscopia, rinoscopia, uroscopia... $\quad$ oftalmoscopia, otoscopia, radioscopia, rinoscopia, uroscopia...

-terapia: tratamiento, curación (del griego $\theta \varepsilon \rho \alpha \pi \varepsilon i ́ \alpha$ gr. (sust.), 'cuidado, tratamiento'). Forma en portugués: terapia.

terapia, aromaterapia, cromoterapia, electroterapia, farmacoterapia, fisioterapia, fototerapia, helioterapia, hemoterapia, hidroterapia, hipnoterapia, inmunoterapia, ludoterapia, musicoterapia, quimioterapia, radioterapia, sonoterapia, psicoterapia, talasoterapia, termoterapia...

terapia,
cromoterapia, electroterapia,
farmacoterapia, fisioterapia, fototerapia,
helioterapia, hemoterapia, hidroterapia,
hipnoterapia, imunoterapia, ludoterapia,
musicoterapia, quimioterapia,
radioterapia, sonoterapia, psicoterapia,
talassoterapia, termoterapia...




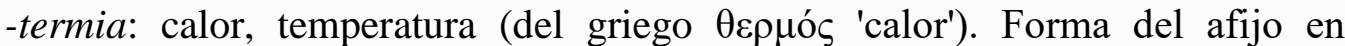
portugués: -termia.

diatermia,

distermia,

diatermia, distermia, eletrotermia,

electrotermia, hipertermia, hipotermia... $\quad$ hipertermia, hipotermia...

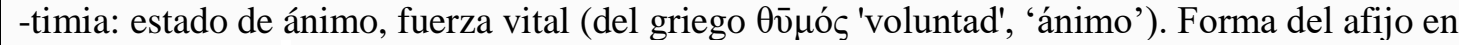
portugués: -timia.

alexitimia, anfitimia, atimia, alexitimia, anfitimia, atimia,
catatimia, ciclotimia, distimia, hipertimia, catatimia, ciclotimia, distimia, hipertimia, lipotimia... lipotimia...

-trofia: alimentación, nutrición (del griego - $\tau \rho o \varphi^{i} \alpha$ 'nutrición'). Forma del afijo en portugués: trofia.

amiotrofia, atrofia, cacotrofia, distrofia, eutrofia, hipertrofia, hipotrofia, leucodistrofia, oligotrofia... amiotrofia, atrofia, cacotrofia, distrofia, eutrofia, hipertrofia, hipotrofia, leucodistrofia, oligotrofia...

Anexo 2 - Bloque 2. Redes semánticas

Anatomía. Fisiología

Español: acrocefalia, alvéolo/alveolo, areola/aréola, braquicefalia, cartílago, celiaco/celíaco, cerebro, clítoris, esfínter, esternón, estrógeno, inión, médula, metabolito, mielocito, nefrona/nefrón, omóplato/omoplato, otolito, perineo, peroné, tráquea, tuétano, uréter...

Portugués: acrocefalia, alvéolo, aréola, braquicefalia, cartilagem, celíaco, cérebro, clitóris/clítoris, esfíncter/esfincter, esterno, estrogênio/estrógeno, ínio, medula, metabólito, mielócito néfron/nefrônio, omoplata, otólito, períneo, perónio, traqueia, tutano, ureter...

Bioquímica

Español: actínido, albúmina, almidón, disacárido, estrógeno, glicólisis/glicolisis, glucógeno, hidrógeno, monosacárido, nitrógeno, nucleótido, oligosacárido, oxígeno, polisacárido, sacárido, triglicérido, trisacárido...

Portugués: actinídeo, albumina, amido, dissacarídeo, estrogênio/estrógeno, glicólise, glicogênio, hidrogênio, monossacarídeo, nitrogênio, nucleotídeo, oligossacarídeo, oxigênio, polissacarídeo, sacarídeo, triglicerídio/triglicerídeo/triglicéride, trissacarídeo...

Cardiología

Español: angiectasia, angiomalacia, arritmia, alorritmia, atelocardia, baticardia, bradicardia, braquicardia, cardiaco/cardíaco, cardiomalacia, cardiomegalia, cardiópata, dexiocardia, embolia, estenocardia, flebolito, hipovolemia, isquemia, taquiarritmia, taquicardia...

Portugués: angiectasia, angiomalacia, arritmia, alorritmia, atelocardia, baticardia, bradicardia, braquicardia, cardíaco, cardiomalacia, cardiomegalia, cardiopata, dexiocardia, embolia, estenocardia, flebólito, hipovolemia, isquemia, taquiarritmia, taquicardia... 


\section{Cirugía}

Español: anestesia, angioplastia, alcohol, asepsia, blefaroplastia, catéter, cistopexia, colpopexia, colpoplastia, endodoncia, faloplastia, gastropexia, heteroplastia, mamoplastia, mastoplastia, nefropexia, rinoplastia, toracoplastia, vaginoplastia...

Portugués: anestesia, angioplastia, alcool, assepsia, blefaroplastia, cateter, cistopexia, colpopexia, colpoplastia, endodontia, faloplastia, gastropexia, heteroplastia, mamoplastia, mastoplastia, nefropexia, rinoplastia, toracoplastia, vaginoplastia...

\section{Citología. Histología. Embriología}

Español: acantocito, acardia, acromegalia, adipocito, agranulocito, anafase, anaplasia, astrocito, autofagia, axón, coanocito, condrocito, crinofagia, dendrocito, embriogenia, epicito, eritrocito, esferocito, espermatocito, fagocito, fibrocito, gametocito, granulocito, hepatocito, histiocito, leucocito, linfocito, mastocito, metafase, monocito, nefrona/nefrón, neocito, oligodendrocito, ontogenia, oocito, ovocito, profase, reticulocito, singamia, telofase, trombocito...

Portugués: acantócito, acardia, acromegalia, adipócito, agranulócito, anáfase, anaplasia, astrócito, autofagia, axônio, coanócito, condrócito, crinofagia, dendrócito, embriogenia, epícito, eritrócito, esferócito, espermatócito, fagócito, fibrócito, gametócito, granulócito, hepatócito, histiócito, leucócito, linfócito, mastócito, metáfase, monócito, néfron/nefrônio, neócito, oligodendrócito, ontogenia, oócito, ovócito, prófase, reticulócito, singamia, telófase, trombócito...

\section{Dermatología}

Portugués: acne, alopecia, anetodermia, bromodermia, cianodermia, eritrodermia, esclerodermia, impetigo, leucodermia, leucoplasia, melanodermia, ocrodermia, xantodermia, xerodermia...

Español: acné, alopecia, anetodermia, bromodermia, cianodermia, eritrodermia, esclerodermia, impétigo, leucodermia, leucoplasia, melanoderma, ocrodermia, xantodermia, xeroderma...

Diagnóstico. Terapéutica

Español: algia, alópata, amnioscopia/amnioscopía, analepsia, analgesia, bacterioscopia, biopsia, broncoscopia, colonoscopia, ciclotrón, diatermia, endoscopia, fisioterapia, hidroterapia, homeópata, inmunoterapia, laparoscopia, laringoscopia, naturópata, ortopedia, psicoterapia, quimioterapia, radioterapia, síntoma, terapia...

Portugués: algia, alopatalalópata, amnioscopia, analepsia, analgesia, bacterioscopia, biópsia/biopsia, broncoscopia, colonoscopia, cíclotron, diatermia, endoscopia, fisioterapia, hidroterapia, homeopata, imunoterapia, laparoscopia, laringoscopia, naturapata, ortopedia, psicoterapia, quimioterapia, radioterapia, sintoma, terapia...

Digestivo y hepatología

Español: acalasia, acolia, aerofagia,afagia, apepsia, coprolito, disfagia, dispepsia, enteralgia, gastralgia, gastrectasia, gastrolito, hematemesis, hepatomegalia, odinofagia, proctalgia, taquifagia, tiflectasia...

Portugués: acalasia, acolia, aerofagia, afagia, apepsia, coprólito, disfagia, dispepsia, enteralgia, gastralgia, gastrectasia, gastrólito, hematêmese, hepatomegalia, odinofagia, proctalgia, taquifagia, tiflectasia...

Endocrinología, metabolismo e inmunología 
Español: acetonemia, acidemia, acromaturia, adenia, adipsia, alcoholemia, alérgeno, anafilaxia, anergia, atopia, bilirrubinemia, calcemia, cetonemia, galactosemia, glucemia, hipercalcemia, hipercolesterolemia, hiperglucemia, hipoglucemia/hipoglicemia, linfopenia, lipemia...

Portugués: acetonemia, acidemia, acromatúria/acromaturia, adenia, adipsia, alcoolemia, alergênio, anafilaxia, anergia, atopia, bilirrubinemia, calcemia, cetonemia, galactosemia, glicemia, hipercalcemia, hipercolesterolemia, hiperglicemia, hipoglicemia, linfopenia, lipemia...

Farmacología

Español: alcohol, anodino, antisepsia, bótox, farmacodinamia, farmacognosia, farmacotecnia, farmacoterapia, quimioterapia, sinergia...

Portugués: alcool, anódino, antissepsia, botox, farmacodinamia, farmacognosia, farmacotecnia, farmacoterapia, quimioterapia, sinergia...

\section{Genética}

Español: anticodón, cariotipo, cistrón, codón, exón, fenotipo, genotipo, idiotipo, intrón, mutón, recón, transposón...

Portugués: anticódon, cariótipo, cístron, códon, éxon, fenótipo, genótipo, ideótipo, íntron, múton, récon, transposon...

Ginecología

Español: clitoromegalia, distocia, gonococia, leucorragia, mastalgia, menorragia, menostasia, metralgia, metrorragia, ovarialgia...

Portugués: clitoromegalia, distocia, gonococia, leucorragia, mastalgia, menorragia, menostasia, metralgia, metrorragia, ovarialgia...

Neumología

Español: acapnia, anoxemia, anoxia, atelectasia, asfixia, broncorragia, bronquiectasia, hipercapnia, hiperoxia, hipoxemia, hipoxia, neumolito...

Portugués: acapnia, anoxemia, anoxia, atelectasia, asfixia, broncorragia, bronquiectasia, hipercapnia, hiperoxia, hipoxemia, hipoxia, pneumólito...

Neurología

Español: acatisia, afasia, agnosia, agrafia/agrafía, alalia, alexia, amiotrofia, amnesia, arreflexia, astasia, atrofia muscular, bradilexia, causalgia, discinesia, disfemia, dislalia, dislexia, dispraxia, ecolalia, epilepsia, hidrocefalia, hiperestesia, leucodistrofia, macropsia, neuralgia, neurópata, parestesia, tetraplejia/tetraplejía...

Portugués: acatisia, afasia, agnosia, agrafia, alalia, alexia, amiotrofia, amnésialamnesia, arreflexia, astasia, atrofia muscular, bradilexia, causalgia, discinesia, disfemia, dislalia, dislexia, dispraxia, ecolalia, epilepsia, hidrocefalia, hiperestesia, leucodistrofia, macropsia, neuralgia/nevralgia, neuropata, parestesia, tetraplegia...

Odontología, estomatología,

Español: agenesia dental, alvéolo/alveolo dental, endodoncia, exodoncia, leucoplasia, odontalgia, ortodoncia, periodoncia...

Portugués: agenesia dental, alvéolo dental, endodontia, exodontia, leucoplasia, odontalgia, ortodontia, periodontia... 
Oftalmología

Español: ablefaria, acromatopsia, anisocoria, buftalmia, corectasia, coroplastia, cromatopsia, dictiopsia, diplopia, discromatopsia, exoftalmia, fotopsia, lagoftalmia, macropsia, micropsia, miope, oftalmia, queratomalacia, sinequia, xantopsia, xeroftalmia...

Portugués: ablefaria, acromatopsia, anisocoria, buftalmia, corectasia, coroplastia, cromatopsia, dictiopsia, diplopia, discromatopsia, exoftalmia, fotopsia, lagoftalmia, macropsia, micropsia, míope, oftalmia, ceratomalacialqueratomalacia, sinequia, xantopsia, xeroftalmia...

Otorrinolaringología

Español: ageusia, acúfeno, amixia, anacusia, anosmia, cacosmia, cofemia, disgeusia, disosmia, hipoacusia, hipogeusia, hiposmia, otalgia, otodinia, parosmia, rinalgia, rinorragia, sialolito...

Portugués: ageusia, acuofênio/acufeno, amixia, anacusia, anosmia, cacosmia, cofemia, disgeusia, disosmia, hipoacusia, hipogeusia, hiposmia, otalgia, otodinia, parosmia, rinalgia, rinorragia, sialólito...

Patología general

Español: acatastasia, acinesia, acromegalia, adenomegalia, agenesia, alergia, algia, analgesia, anemia, aplasia, astenia, atipia, atrofia, caquexia, catalepsia, displasia, distrofia, epidemia, hemiplejia/hemiplejía, hemofilia, hemorragia, hipercinesia, hiperemia, hiperplasia, hipertermia, hipoplasia, hipotermia, leucemia, lipotimia, mialgia, narcolepsia, neoplasia, pandemia, parálisis, parestesia, plétora, sarampión, septicemia, sudamina...

Portugués: acatastasia, acinesia, acromegalia, adenomegalia, agenesia, alergia, algia, analgesia, anemia, aplasia, astenia, atipia, atrofia, caquexia, catalepsia, displasia, distrofia, epidemia, hemiplegia, hemofilia, hemorragia, hipercinesia, hiperemia, hiperplasia, hipertermia, hipoplasia, hipotermia, leucemia, lipotimia, mialgia, narcolepsia, neoplasia, pandemia, paralisia, parestesia, pletora, sarampo, septicemia, sudâmina...

Patología infecciosa

Español: bacilemia, bacteriemia, blenorragia, carate, difteria, ébola, gonococia, piemia, rubeola/rubéola, sarampión, septicemia, toxemia, tularemia, viremia...

Portugués: bacilemia, bacteriemia, blenorragia, caraté, difteria, ebola, gonococia, piemia, rubéola, sarampo, septicemia, toxemia, tularemia, viremia...

Psicología. Psiquiatría

Español: abasia, abulia, acrofobia, agorafobia, alexitimia, androfobia, anfitimia, anhedonia, anorexia, antropofobia, atimia, bulimia, catatimia, catatonía/catatonia, ciclotimia, claustrofobia, distimia, esquizofrenia, euforia, fobia, fotofobia, hebefrenia, hidrofobia, hipertimia, histeria, homofobia, narcolepsia, oligofrenia, ortorexia, psicópata/sicópata, psicoterapia, vigorexia, xenofobia, zoofobia...

Portugués: abasia, abulia, acrofobia, agorafobia, alexitimia, androfobia, anfitimia, anedonia, anorexia, antropofobia, atimia, bulimia, catatimia, catatonia, ciclotimia, claustrofobia, distimia, esquizofrenia, euforia, fobia, fotofobia, hebefrenia, hidrofobia, hipertimia, histeria, homofobia, narcolepsia, oligofrenia, ortorexia, psicopata, psicoterapia, vigorexia, xenofobia, zoofobia...

Traumatología, reumatología 
Español: acondroplasia, adinamia, amelia, artralgia, cervicalgia, condromalacia, coxalgia, diastrofia, fibromialgia, gonalgia, lumbalgia, miastenia, miomalacia, osteomalacia, osteópata, osteopenia, osteoplastia, reúma/reuma, sacralgia...

Portugués: acondroplasia, adinamia, amelia, artralgia, cervicalgia, condromalacia, coxalgia, diastrofia, fibromialgia, gonalgia, lombalgia, miastenia, miomalacia, osteomalacia, osteopata, osteopenia, osteoplastia, reuma, sacralgia... 